\title{
Psychological Effects: Making Human Resources Management Easier
}

\author{
Lu Lingxia, Wang Yanxun, Wang Shuang
}

Hebei University of Economics and Business, Shijiazhuang 050061, China

Keywords: Psychological effects; logical; human resource management

Abstract. It is necessary for every human resource manager to understand psychology and the regularity between employee's psychology and behavior, and make use of these rules to manage and motivate employees so as to make the management work easier and more effective. This paper introduces the connotation of psychological effects such as loss aversion effect, anchoring effect, adaptive bias, availability effect, emotional priming effect, and then discusses these psychological effects in recruitment, training of new employees, etc. This paper focus on the application of psychological effects in human resource management, such as recruitment, new employee training, performance evaluation, compensation design and employee motivation , and then puts forward practical suggestions.

\section{Introduction}

From Simon's view of "Bounded rationality model" to Kahneman's "prospect theory", to the "behavioral decision theory" which many scholars are keen to study, more and more scholars and management practitioners begin to recognize the fact that people are not completely rational people. Human resource management is complex because of the complexity of human psychology; human behavior does not always accord with logic. In social perception, people's judgments and decisions are often influenced by their emotions, intuition, attention and existing memories, rather than always rational thinking, and even, non - rational thinking mode often becomes the "protagonist" of our thinking world ${ }^{[1]}$. Some psychological effects involved in this paper are the summarization of the law of people's behavior under the non - rational thinking mode.

Understanding and utilizing these psychological effects can make human resource managers more relaxed and effective in recruitment, new employee training, performance assessment, salary design and employee incentives.

\section{Loss Aversion Effect: Salary and Incentives}

It was also 1,000 Yuan, which is bigger between the pain of losing 1000 Yuan or the happiness of getting 1000 Yuan? The traditional rational economic man assumes that the answer is "equal". However, people are not completely rational. One of the most important aspects of kahneman's prospect theory is the loss aversion theory: people's response to "loss" is much greater than people's response to "gain". Kahneman argues that people's "loss aversion factor" (the ratio of disgust to the loss of something to the degree of pleasure that comes with acquiring the same value) is usually between 1.5 and $2.5^{[1]}$.

In salary management, human resource managers can take advantage of employees' loss aversion and improve employees' satisfaction with salary.

In salary structure, the two most weighted items are the post wage and the performance salary (for the sake of convenience, the other income is omitted below). The post wage is relatively stable, and the performance salary is paid according to the employee's monthly performance appraisal. Which of the following statements is better for monthly income?

1. The post wage is 4000 Yuan in each month; the performance salary is determined by assessment score, up to 2000 Yuan;

2. The total monthly salary is 6000 Yuan, and 2000 Yuan is assessed from the total salary. The assessment score determines the performance salary.

These two types of compensation, rationally, are the same thing. However, employees' psychological feelings are quite different. In the first way, people feel "get" and receive different amounts of bonuses 
every month. In the second way, people feel "lost" because each month they are "deducted" from 6,000 Yuan.

People feel much more strongly about being "deducted" from time to time than the occasional "get" bonus. So, make use of people's loss aversion, can change the description of compensation system, and let employees to produce the feeling of "get", rather than "lost", which can improve employees' satisfaction with salary. In the same way, in order to improve the enthusiasm of employees, it is to praise the achievements of their work, or to criticize their work deficiencies? This is actually a question of either "positive incentives" or "negative incentives" are effective. According to the people's loss aversion, in general, motivation should be based on "positive motivation" and "negative incentive" as auxiliary. Of course, "negative incentives" can be used appropriately for employees who are "infrequently taught" or made major mistakes.

\section{Anchoring Effect: Recruitment and New Employee Training}

Anchoring, refers to our first impression of someone or something, like anchor sink to the bottom of the ocean, fixed us firmly in the in situ, thus determines our judgment and evaluation[2]. First impression always is inaccurate, and human resource managers should avoid the impact of anchoring effect, in order to make a fair assessment of the staff, and then can use the anchoring effect to manage staff.

In recruitment interview, anchoring effect often makes recruitment examiners decide to hire only with a good first impression of applicants. The first impression may come from a beautiful resume, or a decent dress, or an excellent performance of the first interview topic, a good impression at the beginning of the interview, anchoring the examiner's ideas like an anchor. It is difficult to Adjustment. In order to avoid the influence of the anchoring effect, the examiner should determine the key competencies and their weights according to the post requirements in the preparation for the interview, and adopt the structured interview method as far as possible. In the structured interview, each interview question is for the evaluation of the indicators, and there is a clear evaluation criterion. In this way, even if the applicant's first answer of the question is excellent, it is only the first one that has a high score, which does not affect the score of other indicators.

On the other hand, the impression that the examiner gives the candidate in the hiring process also has an anchoring effect in the other person's mind. A new employee's first impression of the company comes from his view of the examiner. Therefore, the professional performance and affinity of the examiners will greatly help the new employees have a sense of identity with the enterprise.

Anchoring effects can also be used in the training of new entrants. The first month of the new employee is a critical period for the first impression of the company, and also an important stage for establishing identity and satisfaction. The HR manager shall carefully design the training and guidance for the new employees in the first month. Specifically, the following contents should be paid attention to: first, the company's history, the company's values and the future vision of the company will help the new employees to develop a sense of identity and mission to the company; Secondly, clear organizational structure, standardized workflow and reasonable and fair company system will make a good impression on the new employees' "management norms". Third, clear job responsibilities let new employees know their work content and work requirements clearly; fourthly, the work style and friendly attitude of direct supervisors and colleagues will help new employees build a sense of belonging more quickly.

\section{Adaptive Bias: Incentives and Incentives}

The prince and princess in the fairy tale finally get married after suffering, we think they will be happy after marriage for a lifetime, but perhaps a month later the prince will not be happy, the princess began to complain about the boredom of marriage. This is how people adapt to the environment. Adaptability refers to the gradual weakening of people's response to environmental stimulus over time ${ }^{[3]}$. According to Maslow $^{[4]}$, a famous psychologist, there are countless "heaven" in one's life, but people can only stay in each "heaven" for a very short time. When people struggle to pursue a goal, they often feel that goal is the 
most important thing in their life, and he does experience happiness when he reaches his goal, just like entering the "heaven". But soon, he will come out of "heaven", because he quickly adapted to what he already has.

"Adaptability bias" means that human resource managers often neglect the adaptability of employees, thus overestimating the impact of some systems and measures on employees after a period of time. For salary hikes, HR executives often consider this to be the best way to motivate employees. But the fact is that just started a wage increase, can really play the incentive effect obviously, but after two or three months, the staff can produce adaptability, used for high wages, and they return to the enthusiasm before they get a raise.

For the decision makers of human resource management, first of all, we should adjust their adaptive bias, and then understand the rules of employees' adaptation, and make use of the rules to formulate incentives that are not easy to adapt. So, what is easy to adapt to, and what is not easy to adapt to?

Firstly, it is easier for people to adapt to material incentives than to spiritual incentives ${ }^{[3]}$. For most employees, the satisfaction of material needs is the most basic and the most important demand. The improvement of welfare, the increase of wages and so on will make the employees happy, but the happiness will soon disappear. Because people quickly adapt to these changes that these measures no longer have incentive effect. The research results of behavioral decision-making show that the adaptability of people to spiritual and material things is different. It is not easy for people to adapt to spiritual things. For spiritual satisfaction, the incentive effect is longer than material income. Therefore, managers should pay attention to the satisfaction of employees' spiritual needs, such as recognition of outstanding employees, regular entertainment activities, praise from supervisors, respect for employees, help employees obtain a sense of achievement in their work, and so on. These measures will produce better and longer-term incentives on the employees.

Secondly, staffs are not easy to adapt to the incentive mode of pulse change ${ }^{[3]}$. For the children who have been living in a rich family always cannot have a sense of happiness, however, children who come from common family are easy to be filled with great joy when they sometimes receive a toy. Similarly, employees tend to adapt to things that are static, while things that change in a pulse tend to affect their behavior more easily. Certainly, for company policies and post wages, belonging to "hygiene factor", are relatively stable and must not be constantly changing. However, for performance-related pay, welfare and spirit incentive measures, managers can change the forms to avoid employee adaptation and serve as an "incentive factor". Specifically, first of all, merit pay must be linked to the monthly performance of employees, so as to avoid the phenomenon of constant performance-related pay, so that the changing performance pay can produce an incentive effect on a monthly basis. Secondly, the form of payment of employee benefits will also be changed as much as possible. Avoid inflexibility. Thirdly, pay attention to spiritual motivation. Spiritual incentives are not easy to adapt because their content is always in the form of change.

\section{Availability Effect: Recruitment and Assessment}

If the media recently reported two consecutive plane crashes, will it affect your choice of travel tools? Will you tend to choose a train over a plane? Is it easier to make up your mind to quit smoking when you hear that your friend is suffering from lung cancer as a result of long-term smoking? Psychological research shows that the information that affects people's decision-making is often the easiest to extract from memory. "Follow your heart" is the most common thought pattern in our brain ${ }^{[1]}$.

Availability effect, also known as "the principle of least effort", refers to when people need to make a judgment, often based on the easiest way to get information or the first to think of, rather than dedicated to dig more accurate information ${ }^{[5]}$.

In human resource management, the accessibility effect often affects the accurate evaluation of the applicant's ability by the recruitment examiner, which also affects the impartial assessment of subordinates' performance by supervisors. 
When screening resumes, it is easier to get information from a candidate's photos into the hiring manager's mind, because people look at pictures more easily than reading words. During the interview, the applicant's appearance is more likely to leave a deep impression on the examiners, thus affecting the employment decision. "Judging by appearances" is an unavoidable mistake, because it conforms to the "principle of least effort" in people's thinking mode. Judge a book by its cover, here is not, of course, mean according to whether the appearance is beautiful and the figure is handsome, it is the applicant's appropriate dress, confident, capable and affinity, and the external factors that are easy to observe affect the examiner's judgment, however, factors such as ability, character and values, which are more closely related to the post, are ignored. In order to avoid judging a person by appearance, the recruiter should try his best to use the structured interview mentioned above, evaluate the key competency index of the position more objectively, and then make the correct employment decision.

In performance appraisal, the examiner is also vulnerable to the influence of the availability effect. Since the assessment is periodic, recent events and quantifiable results are more likely to be the basis for the assessment of department managers. As for the early and unquantifiable tasks, it is not easy to be extracted from the manager's memory. As a result, some employees know this well and do not try their best in normal work, but when approaching the assessment, in order to get a good result, they will be particularly active in front of the leaders. In order to circumvent the availability effects, the influence of the managers should get into the habit of "performance record", whether can be quantified or cannot be quantified, as long as it is "critical events" of this position, should be recorded at any time, as the inspection period at the end of the assessment basis. In this way, performance evaluation can be made objectively and impartially.

\section{Emotional Priming Effect: Working Atmosphere}

People will smile when they feel happy. But if you make a smile first, will you feel better? Let us do a little experiment: put your pencil across your teeth for half a minute and put your pen down. Do you feel any different? Next, put the pencil up again, bite the end of the pencil with your teeth, and keep it for half a minute. What is the difference in your mood between when you bite the end of the pencil and when you bite the pencil horizontally? Are you happier in the first case and depressed in the latter? If you look closely, you'll find that your face is "smiling" while you're biting your pencil horizontally, while your face is "frowning" when you're biting a pencil vertically. Your expression affects your mood. This is what kahneman calls the "unwitting pencil" of emotional priming experiments ${ }^{[1]}$.

The emotional priming effect refers to the stimuli (or information) that we receive before starting our next thoughts, feelings, and emotions associated with it. Emotional priming is everywhere, such as an action, a string of words, a sound... We will have associations and emotions associated with these things ${ }^{[1]}$.

In human resource management, we can use the emotional priming effect to improve the company's working atmosphere. In many companies, especially in the service industry, employees will sing or do exercises together in the morning, just to cheer up and start the day with a good mental state. This is actually using the effect of emotional priming. Of course, to start the employee's good mood, not necessarily through singing or doing exercises to achieve, managers can also make good use of the morning and weekly meetings, appropriate praise and encouragement, will also start the staff passion. In addition, the company's environment can also become an important emotional starting factor, clean and tidy, beautiful and comfortable office environment, will allow employees to enter the company with a happy working mode.

Emotion priming effect, not only in at the start of work, at working gap, especially after work fatigue, a cup of coffee, a little dessert or a piece of music, will also be a mood "doping", and "cheer "the employees up at work. Now more and more companies are opening "relaxation rooms" in the workplace, which is very popular among employees and is very helpful for employees' emotional regulation. 


\section{Conclusion}

In recent years, behavioral decision science has attracted more and more attention from psychologists, management scientists and economists. Its findings have been widely used in education, economics, management, marketing and other fields. In fact, human resource management is more closely related to psychology.

Human resource management is an art of dealing with people. Human psychology is mysterious and complex, but there is regularity. Behavior decision science experts' studies show that people in the judgment and decision is influenced by psychological factors, will produce many psychology effect, such as loss aversion effect, anchoring effect, adaptive bias, availability deviation, emotional priming effect and so on.

Any psychological effect may be utilized and an unexpected effect will be received if the human resource management area exploits those psychological effects.

\section{Acknowledgment}

This paper is a periodical achievement of 2015 Hubei University of economics and economics teaching research project (2015JYZ02) and the humanities and social science research project (GH161045) of Hubei University of higher learning.

\section{References}

[1]. Daniel Kahneman (Translator Hu Xiaojiao etc). Thinking, Fast and Slow[M]. Citic Press, Jul. 2012, P15-P21, P36 P38, P257 P258.

[2]. Daniel Kahneman, Paul Slovic, Amos Tversky. (Translator Fang Wen etc). Judgment under uncertainty: Heuristics and biases[M]. People's University Publication House, Sep. 2008, P189-P191.

[3]. Christopher K. Hsee. Don't be a normal fool (2nd edition)[M]. Machine Press, April 2007, P247-P62.

[4]. Dan Ariely. Predictably Irrational: The Forces That Shape Our Decisions[M]. Citic Press, Nov. 2008, P27.

[5]. Xue Qiuzhi. Behavioural economics: theory and application [M]. Fudan University Press, Nov.2003, P79-P81. 